\title{
Evaluation of antioxidant, antitumor and immunomodulatory properties of polysaccharide isolated from fruit rind of Punica granatum
}

\author{
MANU M. JOSEPH ${ }^{1}$, S.R.ARAVIND ${ }^{1}$, SHEEJA VARGHESE ${ }^{1}$, S. MINI $^{2}$ and T.T. SREELEKHA ${ }^{1}$ \\ ${ }^{1}$ Laboratory of Biopharmaceuticals, Division of Cancer Research, Regional Cancer Centre; \\ ${ }^{2}$ Department of Biochemistry, University of Kerala, Trivandrum, Kerala, India
}

Received June 21, 2011; Accepted September 27, 2011

DOI: $10.3892 / \mathrm{mmr} .2011 .638$

\begin{abstract}
Polysaccharide (PSP001) isolated from Punica granatum was evaluated for its radical scavenging and antitumor activities in vitro. The fruit of Punica granatum (pomegranate) has been reported to possess several vital biological activities. This study aimed to determine the antioxidant and anticancer properties of polysaccharide PSP001 isolated from the fruit rind of pomegranate. Antioxidant activities were evaluated using various assays such as the 1,1-diphenyl-2-picryl-hydrazil (DPPH) radical scavenging assay, ferric reducing antioxidant power assay, linoleic acid emulsion thiocyanate assay, and superoxide, hydroxyl and nitric oxide radical scavenging assays. PSP001 exhibited a dose-dependent enhancement in activity using concentrations from 10 to $1000 \mu \mathrm{g} / \mathrm{ml}$ except for the DPPH assay for which the highest activity was obtained at $200 \mu \mathrm{g} / \mathrm{ml}$. The anticancer properties of PSP001 evaluated on MCF-7 (breast cancer), KB (nasopharyngeal carcinoma) and K562 (leukemia) cells by MTT assay indicate its potential as an antitumor agent. An IC50 value of $97.21 \pm 1.06 \mu \mathrm{g} / \mathrm{ml}$ and $52.8 \pm 0.9 \mu \mathrm{g} / \mathrm{ml}$ were obtained following $72 \mathrm{~h}$ incubation for MCF-7 and K562 cells, respectively. PSP001 showed in vitro growth stimulatory effect on isolated normal lymphocytes, and a proliferative index of $1.21 \pm 0.01$ at a concentration of $1000 \mu \mathrm{g} / \mathrm{ml}$ was obtained, indicating immunomodulatory activity. The results of the present study indicate that further studies are required on PSP001 in order to use this compound as an antitumor agent.
\end{abstract}

\section{Introduction}

Polysaccharides are a structurally diverse class of macromolecules of relatively widespread occurrence in nature.

Correspondence to: Dr T.T. Sreelekha, Scientific Officer Grade 1, Division of Cancer Research, Regional Cancer Centre (RCC), Trivandrum-11, Kerala, India

E-mail: lekhasree64@yahoo.co.in

Key words: Punica granatum, polysaccharide, antioxidant activity, antitumor activity, immunomodulation
They play major roles in the growth and development of living organisms. In the last few decades, the biological activities of polysaccharides have attracted more and more attention in medicine (1). Pomegranate (Punica granatum) belongs to the family of Punicaceae and is grown mainly in the Near East, India, Spain, Israel and the United States. In folk medicine, the astringent properties of this fruit have been used to treat various ailments such as cuts, sore throats, tapeworms, dysentery, and gum disease (2). Antitumor, antibacterial, antidiarrhoeal, antifungal, antiulcer, and antioxidant pharmacological properties have been reported for various extracts/constituents of different parts of this plant species (3). The medicinal properties of polysaccharides mainly depend on its chemical structure. A number of polysaccharides with $\beta-1 \rightarrow 3$ backbones are reported for their antitumor and immunomodulatory activities. We have isolated a polysaccharide from the fruit rind of Punica granatum, which is a galactomannan with a molecular weight of $110 \mathrm{kDa}$ with a $\beta-1 \rightarrow 3$ galactopyranose backbone and $\beta-\mathrm{D}$ mannopyranose and $\alpha-\mathrm{D}$ mannopyranose side chains (4).

Reactive oxygen species (ROS) are formed and degraded by all aerobic organisms and can readily react with the majority of biomolecules including proteins, lipids and nucleic acids. ROS is involved in various physiochemical processes and diseases such as aging, cancer, atherosclerosis, neurodegenerative diseases (Alzheimer's and Parkinson's diseases) and AIDS $(5,6)$. Antioxidants are compounds that inhibit or delay the oxidation process by blocking the initiation or propagation of oxidizing chain reactions. There are two basic categories of antioxidants, synthetic and natural. The uses of synthetic antioxidants are restricted by their carcinogenic properties (7). Certain plants are known to possess potent antioxidant properties and are a significant source of natural antioxidants $(8,9)$. Therapy with free radical scavengers (antioxidants) therefore has the potential to prevent, delay or ameliorate a number of the above-mentioned disorders (10). Among various naturally occurring substances, polysaccharides have proven to be useful candidates in the search for effective, non-toxic substances with antioxidant activity (11-13). Among the most promising biopharmacological activities of polysaccharides, immunomodulatory and antitumor effects are of high priority (1). A number of the chemical compounds 
identified as specific agents for killing cancer cells are also toxic to normal cells, thereby limiting their usage in therapy. Numerous antitumor polysaccharides have been isolated from plants, mushrooms, yeasts, algae and lichens and the majority of them have been found to be non-toxic to normal cells and are also found to enhance the immune system of the host (14-16). Biological activities such as the immunomodulatory and antitumor effects of polysaccharides have attracted more attention recently in medical fields (17-19) and the majority of the polysaccharides act as biological response modifiers, which enhance the immune response (20).

In view of the impact of polysaccharides to human health, the present study aimed to investigate the antioxidant, anticancer and immunomodulatory activities of the polysaccharide PSP001. Since reactive oxygen species (ROS) play a major role in the development of cancer, an antioxidant compound with anticancer properties may be a promising target of further research.

\section{Materials and methods}

Materials and chemicals. Fully ripened fruits of pomegranate were collected from the Thiruvananthapuram District of Kerala, India. The cancer cell lines MCF-7 (breast cancer), KB (nasopharyngeal carcinoma) and K562 (leukemia) were obtained from the National Centre for Cell Science, Pune, India. The Spectra/Por 12-14,000 MW dialysis membrane was from Spectrum Laboratories (RC membrane, Spectrum Laboratories, Rancho Dominguez, CA, USA). SephadexG-200 was from Pharmacia LKB, Biotechnology AB (Uppsala, Sweden) DMEM from Gibco (Invitrogen, Carlsbad, CA, USA) and Ficoll-Paque ${ }^{\mathrm{TM}}$ from GE Healthcare (Bio-Sciences AB, Uppsala, Sweden). All other reagents were purchased from Sigma Aldrich (St. Louis, MO, USA) and were of grade AR.

Isolation and purification of polysaccharide PSP001. Ripened fruits of Punica granatum were obtained, the fruit rind was shade-dried and $200 \mathrm{~g}$ of the powdered material was used for the isolation of polysaccharide by standard protocols $(21,22)$, with modifications. Briefly, the powdered material was treated with petroleum ether for $72 \mathrm{~h}$ to remove any fat present, followed by hot-water extraction using Soxhlet apparatus. The filtrate was subjected to ethanol precipitation at $4^{\circ} \mathrm{C}$, the precipitate was dissolved in distilled water and dialysis was performed against double distilled water using 12-14,000 MW membrane. The solution was treated with chloroform to remove protein, if present, in a separation funnel until the interphase became clear. The steps were repeated several times until the water chloroform interphase became clear. The aqueous phase was again dialyzed, concentrated and precipitated with ethanol. Polysaccharide precipitate was collected by centrifugation at $12,000 \mathrm{rpm}$ at $4^{\circ} \mathrm{C}$, redissolved in distilled water and lyophilized.

The polysaccharides were purified by gel filtration chromatography using Sephadex G-200; 0.001 M phosphatebuffered saline (PBS) was used as the eluent and the purified product was again lyophilized. Total carbohydrate content was determined by Dubois's method (23), using D-glucose as the standard.
$D P P H$ radical scavenging assay. The radical scavenging effects of PSP001 on a 1, 1-diphenyl-2-picryl-hydrazil (DPPH) radical were estimated through the methods of Magalhaes et al (24). Various concentrations of samples and standards $(3 \mathrm{ml})$ were mixed with $1 \mathrm{ml}$ of $0.1 \mathrm{mM}$ of DPPH and the mixture was agitated vigorously and allowed to incubate at room temperature $\left(25 \pm 3^{\circ} \mathrm{C}\right)$ for $30 \mathrm{~min}$. The scavenging activity was quantified spectrophotometrically at $507 \mathrm{~nm}$ against $95 \%$ ethanol as blank. Ascorbic acid was used as the standard and the percentage of the DPPH scavenging effect was expressed as the percentage of inhibition from the given formula: \% inhibition of DPPH radical $=\left[\mathrm{A}_{0}-\mathrm{A}_{1} / \mathrm{A}_{0}\right]$ $\mathrm{x} 100$, where $\mathrm{A}_{0}$ was the absorbance of the control and $\mathrm{A}_{1}$ was the absorbance of the sample/standard.

Ferric reducing antioxidant power (FRAP) assay. This assay measures the total antioxidant capacity of the compound and the procedure was conducted according to Benzie and Strain (25), following modifications. The working FRAP reagent was prepared by mixing $300 \mathrm{mM}$ acetate buffer (pH 3.6), $10 \mathrm{mM}$ 2, 4, 6-tripytidyl-s-triazine (TPTZ) solution and $20 \mathrm{mM}$ $\mathrm{FeCl}_{3} \cdot 6 \mathrm{H}_{2} \mathrm{O}$ at a $10: 1: 1$ ratio prior to use and heated to $37^{\circ} \mathrm{C}$ in a water bath. FRAP reagent $(3 \mathrm{ml})$ was added to $100 \mu \mathrm{l}$ of various concentrations of samples and standards. Absorbance was measured at $593 \mathrm{~nm}$ at $0 \mathrm{~min}$ and again after $90 \mathrm{~min}$. Ascorbic acid was used as the standard and changes in the absorbance after 90 min from initial reading were compared and the percentage of inhibition was calculated as described.

Superoxide radical scavenging assay. The scavenging activity of PSP001 towards superoxide anion radicals was measured using the method of Liu et al (11). Superoxide anions were generated in a non-enzymatic phenazine methosulfate-nicotinamide adenine dinucleotide (PMS-NADH) system through the reaction of PMS, NADH and oxygen. It was assayed by the reduction of nitroblue tetrazolium (NBT). Superoxide anion was generated in $3 \mathrm{ml}$ of Tris- $\mathrm{HCl}$ buffer $(100 \mathrm{mM}, \mathrm{pH}$ 7.4) containing $0.75 \mathrm{ml}$ of NBT $(300 \mu \mathrm{M})$ solution, $0.75 \mathrm{ml}$ of NADH $(936 \mu \mathrm{M})$ solution and $0.3 \mathrm{ml}$ of various concentrations of samples and standards. The reaction was initiated by adding $0.75 \mathrm{ml}$ of PMS $(120 \mu \mathrm{M})$ to the mixture. After $5 \mathrm{~min}$ of incubation at room temperature $\left(25 \pm 3^{\circ} \mathrm{C}\right)$, the absorbance at $560 \mathrm{~nm}$ was measured. $\alpha$ tocopherol was used as the standard and the percentage of inhibition was calculated.

Total antioxidant activity in linoleic acid emulsion system. The total antioxidant activity of PSP001 was determined according to the ferric thiocyanate method described by Ilhami et al (26) with slight modifications. The reaction mixture contained $2.5 \mathrm{ml}$ of linoleic acid emulsion system ( $0.28 \mathrm{~g}$ linoleic acid and $0.28 \mathrm{~g}$ Tween- 20 in $50 \mathrm{ml}, 0.2 \mathrm{M}$ phosphate buffer of $\mathrm{pH} 7.0$ ), $2.5 \mathrm{ml}$ of $0.2 \mathrm{M}$ phosphate buffer and $0.5 \mathrm{ml}$ of test and standards at various concentrations. The mixture was incubated at $37^{\circ} \mathrm{C}$ for $120 \mathrm{~h}$. The absorbance was measured at $0 \mathrm{~h}$ and at each $24 \mathrm{~h}$ intervals up to 5 days. The amount of $0.1 \mathrm{ml}$ of the mixture was mixed with $5 \mathrm{ml}$ of $75 \%$ ethanol, $0.1 \mathrm{ml}$ of $30 \%$ ammonium thiocynate and $0.1 \mathrm{ml} 20 \mathrm{mM}$ ferrous chloride in $3.5 \% \mathrm{HCl}$ and allowed to stand at room temperature for exactly $3 \mathrm{~min}$. Absorbance was then read at $500 \mathrm{~nm}$ against a suitable blank. Ascorbic acid 


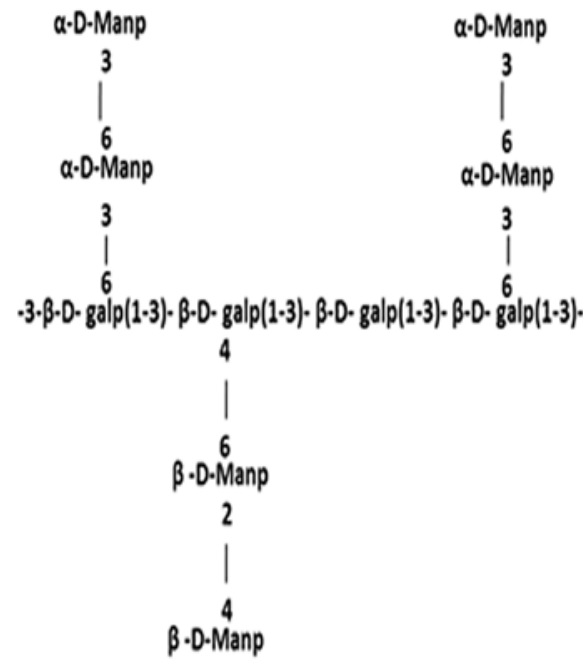

Figure 1. Proposed structure of polysaccharide PSP001.

was used as the standard and the percentage of inhibition was calculated.

Nitric oxide radical scavenging. Nitric oxide generated from sodium nitroprusside in aqueous solution at physiological $\mathrm{pH}$ interacts with oxygen to produce nitrite ions, as measured by Griess reaction (27). The reaction mixture $(3 \mathrm{ml})$ containined $10 \mathrm{mM}$ sodium nitroprusside in PBS and samples/standards at various concentrations. The mixture was incubated at $25^{\circ} \mathrm{C}$ for $150 \mathrm{~min}$. After the incubation, $1 \mathrm{ml}$ of the mixture was removed and added to $1 \mathrm{ml}$ of Griess reagent (1\% sulfanilamide, $0.1 \%$ naphthylethylene diamine dihydrochloride in $2 \% \mathrm{H}_{3} \mathrm{PO}_{4}$ ) and the absorbance was measured at $546 \mathrm{~nm}$. $\alpha$ tocopherol was used as the standard and the percentage of inhibition was calculated.

Hydroxyl radical scavenging assay. Hydroxyl radical scavenging activity was measured comparing deoxyribose and PSP001 for hydroxyl radical generated by the $\mathrm{Fe}^{3+}$-ascorbateEDTA- $\mathrm{H}_{2} \mathrm{O}_{2}$ system (Fenton reaction) using the method of Kunchandy and Rao (28). The reaction mixture $(1 \mathrm{ml})$ contained $100 \mu 1$ 2-deoxy-2-ribose ( $28 \mathrm{mM}$ in $20 \mathrm{mM}$ phosphate buffer, $\mathrm{pH} 7.4), 500 \mu \mathrm{l}$ of different concentrations of samples and controls, $200 \mu \mathrm{l} 1.04 \mathrm{mM} \mathrm{FeCl}_{3}, 100 \mu \mathrm{l} 1 \mathrm{mM} \mathrm{H}_{2} \mathrm{O}_{2}$ and $100 \mu \mathrm{l}$ ascorbic acid, was incubated at $37^{\circ} \mathrm{C}$ for $1 \mathrm{~h}$. Thiobarbituric acid $(1 \%)$ and trichloroacetic acid $(2.8 \%)$ were added and incubated at $100^{\circ} \mathrm{C}$ for $20 \mathrm{~min}$. After rapid cooling the absorbance was measured at $532 \mathrm{~nm}$. $\alpha$ tocopherol was used as the standard and the percentage of inhibition was calculated.

Antitumor activity by in vitro proliferation assay. The cell growth inhibition potential of PSP001 was measured against human cancer cell lines MCF-7 (breast cancer), KB (nasopharyngeal carcinoma) and K562 (leukemia) with the MTT (3-[4, 5-dimethylthiazol-2-yl]-2, 5-diphenyltetrazolium) assay (29), which is based on the cleavage of a tetrazolium salt by mitochondrial dehydrogenases in viable cells. Cells were maintained in $10 \% \mathrm{DMEM} / \mathrm{RPMI}$ media in a $\mathrm{CO}_{2}$ incubator with $5 \% \mathrm{CO}_{2}$ and $10 \% \mathrm{FBS}$ at $37^{\circ} \mathrm{C}$. Quantities of $100 \mu \mathrm{l}$ of the cell suspension of $5 \times 10^{3}$ cells/well were seeded in a 96-well plate and $100 \mu \mathrm{l}$ of PSP001 at various concentrations $(0.001-1000 \mu \mathrm{g} / \mathrm{ml})$ and a positive control (doxorubicin) was similarly added to the appropriate wells. The plates were then incubated for 24,48 and $72 \mathrm{~h}$ in a $\mathrm{CO}_{2}$ incubator. After incubation, $20 \mu \mathrm{l}$ MTT $(5 \mathrm{mg} / \mathrm{ml})$ was added to each well and incubation was continued for an additional $2 \mathrm{~h}$. The insoluble formazan crystals formed were solubilised by the addition of $100 \mu \mathrm{l}$ MTT lysis buffer (SDS and dimethyl formamide) followed by an incubation of $4 \mathrm{~h}$ and the absorbance was measured at $570 \mathrm{~nm}$ using a microplate spectrophotometer. The inhibitory rate was calculated as: Inhibitory rate $(\mathrm{Ir}) \%=100-$ Proliferation rate $(\operatorname{Pr})$. $\operatorname{Pr} \%=$ [Abs sample/Abs control] x100.

In vitro lymphocyte proliferation assay. Fresh human blood samples were layered on equal volumes of Ficoll-Paque ${ }^{\mathrm{TM}}$ Plus solution and centrifuged at $800 \mathrm{x} \mathrm{g}$ for $20 \mathrm{~min}$ at $18^{\circ} \mathrm{C}$. The thin white middle lymphocyte layer was collected and washed with PBS twice by centrifugation at $100 \mathrm{x} g$ for $10 \mathrm{~min}$ at $18^{\circ} \mathrm{C}$. The supernatant was discarded and the cells were suspended in 10\% RPMI-1640. The cell number was counted with a hemocytometer and the viability of the cells was examined using the trypan blue exclusion assay. Samples containing cells with $\geq 95 \%$ viability were suspended at a concentration of $2 \times 10^{4}$ cells/well. The lymphocytes were incubated at $37^{\circ} \mathrm{C}$ in a humidified atmosphere of $5 \% \mathrm{CO}_{2}$. The effect of PSP001 on isolated lymphocytes was evaluated using the MTT assay as described above. The mitogen phytohaemagglutinin (PHA) was added to the wells at a concentration of $10 \mu \mathrm{g} / \mathrm{ml}$. The proliferation index (proliferation rate/100) was calculated.

Statistical analysis. Data were expressed as the means \pm standard deviations (SD) of three replicated determinations, and followed by analysis using Graphpad PRISM software version 5.0 (GraphPad Software, USA). One-way analysis of variance was used for repeated measurements and the differences were considered to be statistically significant if $\mathrm{P}<0.05$. The IC50 values were calculated using EasyPlot software.

\section{Results}

Polysaccharide isolation and purification. The yield of purified polysaccharide PSP001 from the fruit rind of pomegranate was $2 \%$. The final product was light brown in color, and was lyophilized and stored at $-20^{\circ} \mathrm{C}$. It was found that, during the isolation process 4-fold volumes of ethanol and twice the volume of chloroform were optimal for the maximum yield of PSP001. The polysaccharide was found to be neutral in $\mathrm{pH}$ and was easily soluble in water. The total sugar content of PSP001 was determined to be $97.6 \%$ using the phenol-sulfuric acid method. Molecular weight determination and structural characterization of the polysaccharide were previously performed and it was revealed to be a galactomannan with a molecular weight of $110 \mathrm{kDa}$ with a $\beta-1 \rightarrow 3$ galactopyranose backbone and $\beta$-D mannopyranose and $\alpha-\mathrm{D}$ mannopyranose side chains (Fig. 1). For structural characterization, partial hydrolysis, periodate oxidation, methylation, hydrolysis, acetylation and trimethylsilylation were carried out and analysed using ${ }^{1} \mathrm{HNMR}$, FABMS and GC-MS (4). 

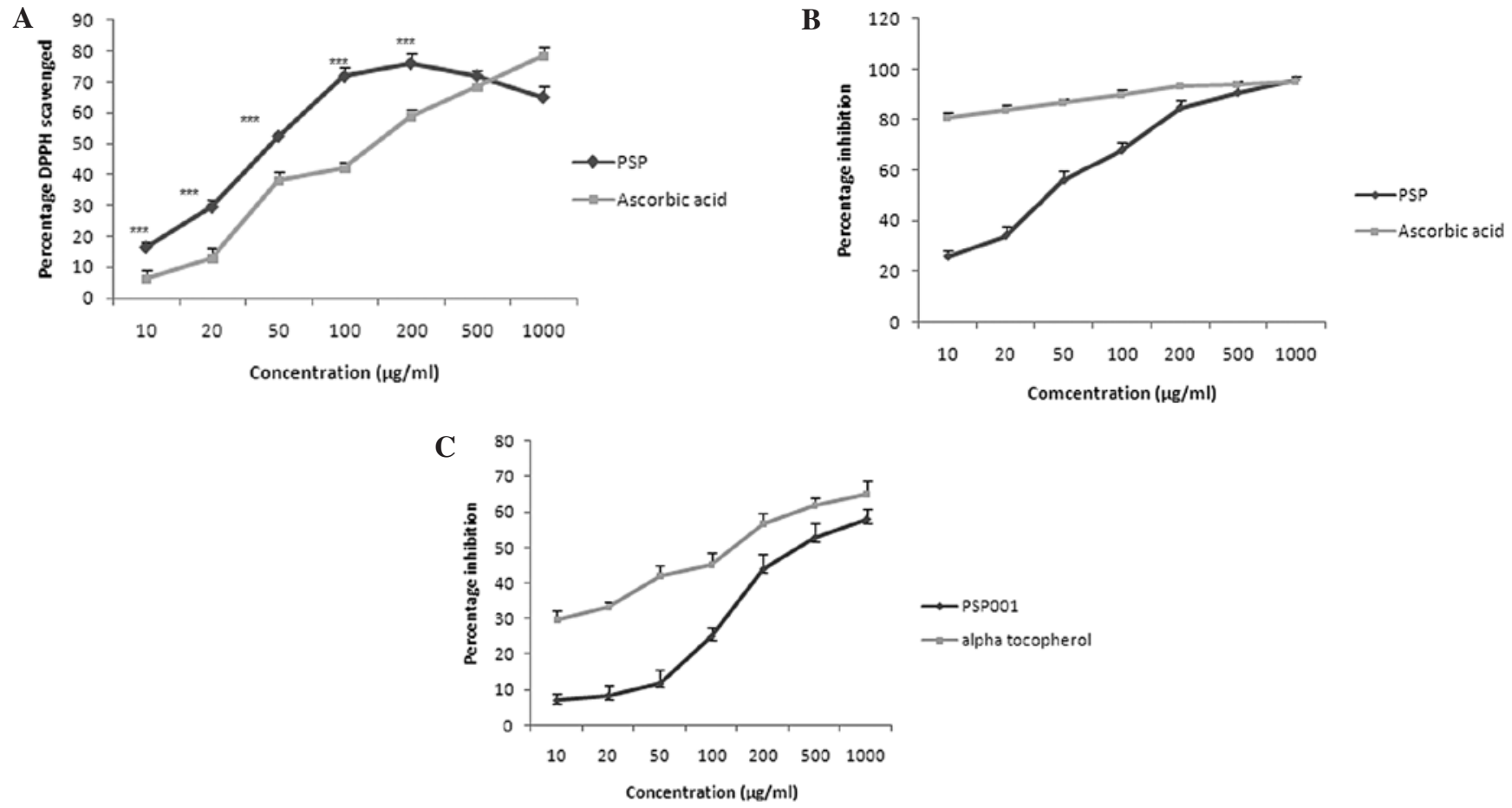

Figure 2. Antioxidant activity of PSP001. (A) DPPH radical scavenging activity of PSP001 and ascorbic acid at various concentrations. (B) FRAP assay using ascorbic acid as the standard. (C) Superoxide radical scavenging assay using $\alpha$ tocopherol as the standard. Results were expressed as the mean \pm SD. Differences between the groups were compared using the Tukey test. $\mathrm{p}<0.001$.

Antioxidant activity of PSP001. The total antioxidant capacity of a compound cannot be determined using a single method, due to oxidative processes. In this study, the radical scavenging ability of PSP001 was evaluated using various antioxidant assays.

$D P P H$ radical scavenging assay. The radical scavenging activity of PSP001 against experimentally generated DPPH ions (Fig. 2A) showed marked scavenging activity even at low concentrations. The scavenging activity increased in a concentration-dependent manner up to $200 \mu \mathrm{g} / \mathrm{ml}$, which exhibited the highest activity (76.09 $\pm 3.4 \%)$; further increases in concentration exhibited no increase in the antioxidant capacity. PSP001 exhibited significantly $(\mathrm{p}<0.001)$ high DPPH scavenging activity compared to the standard ascorbic acid even at low concentrations. The IC50 value of PSP001 was found to be $44.2 \pm 0.8 \mu \mathrm{g} / \mathrm{ml}$, whereas for ascorbic acid it was $149.7 \pm 1.2 \mu \mathrm{g} /$ ml. PSP001 was capable of reducing the stable radical DPPH at an approximately 4-fold higher capacity than ascorbic acid.

FRAP assay. The antioxidant capacity of PSP001 based on the ability to reduce ferric ions was calculated as the percentage of inhibition, as shown in Fig. 2B. There was a gradual increase in antioxidant activity with an increase in concentration, whereas the standard ascorbic acid showed a relatively stable activity even from lower concentrations. PSP001 exhibited an inhibitory activity of $96.05 \pm 1.1 \%$ at a concentration of $1000 \mu \mathrm{g} / \mathrm{ml}$, which was higher than that of ascorbic acid $(95 \pm 2.4 \%)$.

Superoxide radical scavenging assay. The scavenging ability of PSP001 against superoxide ions generated in the PMSNADH-NBT system is shown in Fig. 2C. The superoxide anion scavenging activity of PSP001 exhibited a concentration-dependent increase, and its highest activity of $58 \pm 3.9 \%$ was observed at $1000 \mu \mathrm{g} / \mathrm{ml}$. However, the superoxide radical scavenging activity of PSP001 was observed to be less than the standard $\alpha$ tocopherol. The IC50 values were $399 \pm 2.3$ and $143 \pm 1.4 \mu \mathrm{g} / \mathrm{ml}$ for PSP001 and $\alpha$ tocopherol, respectively.

Total antioxidant activity in the linoleic acid emulsion system. The inhibitory effect of PSP001 and ascorbic acid at various concentrations between 0 and $120 \mathrm{~h}$ is shown in Table I. PSP001 exhibited an increase in activity from 0 to $72 \mathrm{~h}$, whereas ascorbic acid exhibited more activity with a 24-h incubation period, after which the activity decreased. PSP001 showed a significant $(\mathrm{p}<0.01)$ increase in the activity at $72 \mathrm{~h}$ compared with $24 \mathrm{~h}$ and the maximum inhibition was observed at a concentration of $1000 \mu \mathrm{g} / \mathrm{ml}(69.53 \pm 2.5 \%)$. Since PSP001 was capable of scavenging the radical even up to $72 \mathrm{~h}$ as compared to $24 \mathrm{~h}$ of the standard, its action is promising for use in biological systems.

Nitric oxide radical scavenging. The scavenging ability of PSP001 against experimentally generated nitric oxide ions is shown in Fig. 3A. PSP001 showed relatively favourable scavenging activity and is comparable to that of the potent antioxidant $\alpha$ tocopherol. The radical scavenging ability exhibited a concentration-dependent increase and showed $74.90 \pm 3.9 \%$ inhibition at a concentration of $1000 \mu \mathrm{g} / \mathrm{ml}$. The IC50 values were $184 \pm 1.1$ and $136.7 \pm 1.8 \mu \mathrm{g} / \mathrm{ml}$ for PSP001 and $\alpha$ tocopherol, respectively.

Hydroxyl radical scavenging assay. PSP001 exhibited concentration-dependent scavenging activity against hydroxyl 
Table I. Antioxidant activity of PSP001 by linoleic acid emulsion system. ${ }^{a}$

\begin{tabular}{|c|c|c|c|c|c|c|c|c|c|c|c|c|}
\hline \multirow{2}{*}{$\begin{array}{l}\text { Concentration } \\
(\mu \mathrm{g} / \mathrm{ml})\end{array}$} & \multicolumn{2}{|c|}{$0 \mathrm{~h}$} & \multicolumn{2}{|c|}{$24 \mathrm{~h}$} & \multicolumn{2}{|c|}{$48 \mathrm{~h}$} & \multicolumn{2}{|c|}{$72 \mathrm{~h}$} & \multicolumn{2}{|c|}{$96 \mathrm{~h}$} & \multicolumn{2}{|c|}{$120 \mathrm{~h}$} \\
\hline & PSP & ASC & PSP & ASC & PSP & ASC & PSP & ASC & PSP & ASC & PSP & ASC \\
\hline 10 & $10.8 \pm 2.5$ & $13.0 \pm 1.9$ & $11.4 \pm 3.0$ & $42.1 \pm 1.5$ & $9.0 \pm 4.2$ & $42.0 \pm 1.6$ & $15.3 \pm 3.2$ & $21.3 \pm 2.8$ & $11.8 \pm 4.5$ & $24.3 \pm 3.8$ & $24.3 \pm 4.6$ & $16.0 \pm 3.2$ \\
\hline 20 & $11.6 \pm 3.2$ & $17.0 \pm 2.1$ & $13.6 \pm 1.9$ & $37.5 \pm 2.0$ & $13.3 \pm 2.1$ & $47.0 \pm 1.7$ & $19.3 \pm 3.5$ & $29.3 \pm 3.2$ & $22.7 \pm 4.0$ & $28.8 \pm 4.0$ & $28.8 \pm 3.1$ & $20.6 \pm 2.0$ \\
\hline 100 & $12.7 \pm 1.5$ & $25.5 \pm 1.0$ & $10.9 \pm 2.3$ & $74.19 \pm 2.0$ & $29.8 \pm 1.9$ & $42.8 \pm 2.7$ & $29.0 \pm .3 .0$ & $34.1 \pm 1.8$ & $37.8 \pm 3.2$ & $42.1 \pm 3.2$ & $42.1 \pm 4.0$ & $24.3 \pm 3.0$ \\
\hline 200 & $23.6 \pm 1.9$ & $26.7 \pm 2.0$ & $28.0 \pm 2.6$ & $74.4 \pm 2.1$ & $30.2 \pm 3.5$ & $47.8 \pm 1.0$ & $42.6 \pm 4.2$ & $45.3 \pm 1.9$ & $50.0 \pm 1.9$ & $43.5 \pm 4.6$ & $43.5 \pm 3.8$ & $28.03 \pm 2.0$ \\
\hline 500 & $36.4 \pm 2.9$ & $33.9 \pm 3.0$ & $64.0 \pm 1.3$ & $70.7 \pm 3.2$ & $64.8 \pm 1.0$ & $41.0 \pm 4.2$ & $65.9 \pm 3.5$ & $39.8 \pm 2.5$ & $33.3 \pm 4.2$ & $23.4 \pm 3.1$ & $23.4 \pm 3.1$ & $29.0 \pm 1.9$ \\
\hline 1000 & $39.6 \pm 1.5$ & $56.0 \pm 4.0$ & $62.5 \pm 2.9$ & $71.5 \pm 4.2$ & $74.1 \pm 3.8$ & $32.5 \pm 3.9$ & $69.5 \pm 2.5$ & $22.0 \pm 2.9$ & $32.7 \pm 3.2$ & $26.1 \pm 4.1$ & $26.1 \pm 3.9$ & $43.5 \pm 3.4$ \\
\hline
\end{tabular}

${ }^{a}$ Radical scavenging ability of PSP001 and ascorbic acid at various concentrations from 0 to $120 \mathrm{~h}$ incubation period. Results are expressed as mean $\pm \mathrm{SD}$.
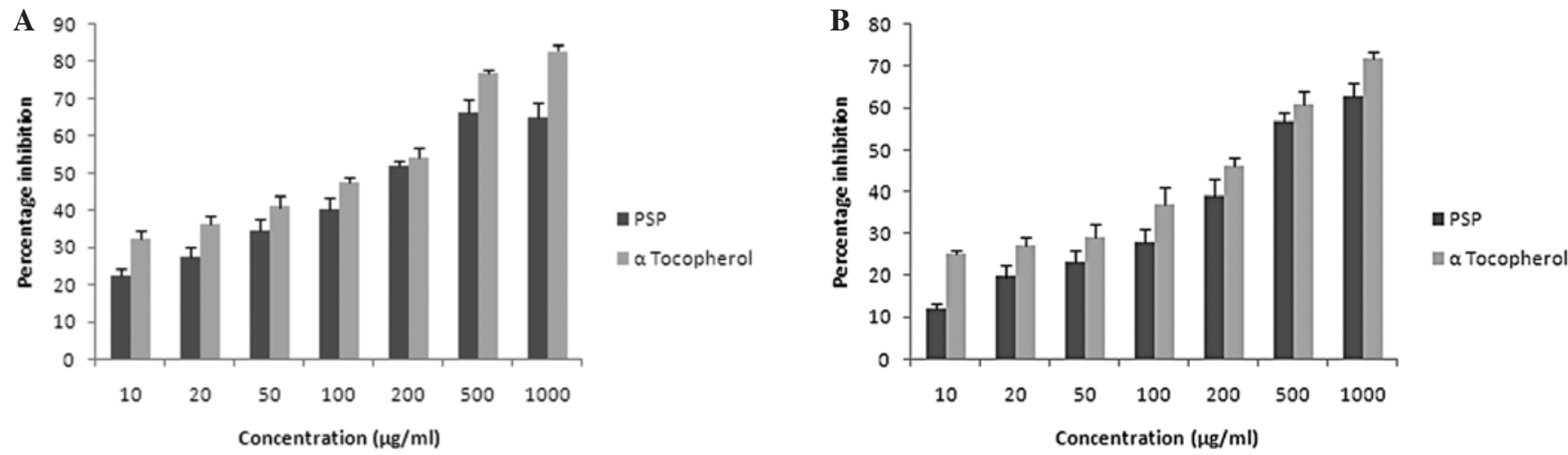

Figure 3. Antioxidant activity of PSP001. (A) Nitric oxide radical scavenging assay using $\alpha$ tocopherol as the standard. (B) Hydroxyl radical scavenging assay using $\alpha$ tocopherol as the standard. Results are expressed as the mean \pm SD. Differences between the groups were compared using the Tukey test.

radical generated in a Fenton reaction system (Fig. 3B). At a concentration of $1000 \mu \mathrm{g} / \mathrm{ml}$, PSP001 demonstrated a radical scavenging ability of $63.90 \pm 3.1 \%$, and IC50 values of $385.4 \pm 2.3$ and $283.8 \pm 1.3 \mu \mathrm{g} / \mathrm{ml}$ for PSP001 and $\alpha$ tocopherol, respectively. The radical scavenging activity of PSP001 is promising and may aid in the prevention or reduction of the progress of various oxidative stress-induced diseases, thereby benefiting human health.

Antitumor and lymphocyte proliferative activity in vitro. The anticancer activity of PSP001 was evaluated by in vitro techniques on MCF-7 (breast cancer), KB (nasopharyngeal carcinoma) and K562 (leukemia) cancer cell lines using the MTT assay. Cytotoxicity on cancer cell lines was evaluated at 24,48 and $72 \mathrm{~h}$ incubation with various concentrations of PSP001. The effect of PSP001 on the viability of cells is shown in Fig. 4. Doxorubicin, a well-known anticancer agent, was used as a positive control at equal concentrations (Table II). A substantial increase in cell growth inhibition was observed after the treatment of PSP001 on MCF-7 cells and an IC50 value of $97.21 \pm 1.06 \mu \mathrm{g} / \mathrm{ml}$ was obtained after $72 \mathrm{~h}$ of incubation (Fig. 4A). The cytostatic effect increased in a concentration-dependent manner up to $200 \mu \mathrm{g} / \mathrm{ml}$ during the incubation periods, after which the activity decreased. Similarly, growth inhibition on oral cancer cell line KB showed the highest value at a concentration of $200 \mu \mathrm{g} / \mathrm{ml}$ $(36.4 \pm 2.4 \%)$ at $72 \mathrm{~h}$ of incubation, but no IC50 value was obtained (Fig. 4B). PSP001 showed its maximum cytotoxicity to be approximately $200 \mu \mathrm{g} / \mathrm{ml}$ for MCF-7 and KB cell lines, whereas in leukemia cell line K562 it exhibited a dose- and time-dependent increase in activity up to a concentration of $1000 \mu \mathrm{g} / \mathrm{ml}(63 \pm 2.9 \%)$. An IC50 value of $52.8 \pm 0.9 \mu \mathrm{g} / \mathrm{ml}$ was obtained during $72 \mathrm{~h}$ of incubation, which was even less than that of $\mathrm{MCF}-7$.

Since the majority of anticancer compounds are toxic to normal cells their application in medicine is highly restricted. The effect of PSP001 at various concentrations on normal lymphocytes was also evaluated using the MTT assay. The compound was found to be both non-toxic to lymphocytes as well as to enhance the in vitro growth of lymphocytes when administered with a mitogen PHA. Fig. 5 shows a significant growth enhancement $(\mathrm{p}<0.001$ in all concentrations compared with the control) on normal lymphocytes. A proliferative index (PI) of $1.21 \pm 0.01$ at a concentration of $1000 \mu \mathrm{g} / \mathrm{ml}$ was obtained. The results of this experiment show that PSP001 exhibited higher growth stimulation even at low concentrations, indicating its potential as an immunomodulatory compound. $\mathrm{T}$ lymphocytes play a crucial role in enhancing the immune functions of organisms. Therefore, examination of alterations in lymphocyte proliferation is the 
Table II. Inhibition rate of doxorubicin on in vitro cell lines. ${ }^{\mathrm{a}}$

\begin{tabular}{|c|c|c|c|c|c|c|c|c|c|}
\hline \multirow{2}{*}{$\begin{array}{l}\text { Concentration } \\
(\mu \mathrm{g} / \mathrm{ml})\end{array}$} & \multicolumn{3}{|c|}{ 24-h inhibition rate } & \multicolumn{3}{|c|}{ 48-h inhibition rate } & \multicolumn{3}{|c|}{ 72-h inhibition rate } \\
\hline & MCF7 & $\mathrm{KB}$ & K562 & MCF7 & $\mathrm{KB}$ & K562 & MCF7 & KB & K562 \\
\hline 0.001 & $6.2 \pm 1.2$ & $6.07 \pm 1.8$ & $6.0 \pm 1.8$ & $8.0 \pm 2.1$ & $7.27 \pm 2.2$ & $11.7 \pm 0.8$ & $12.8 \pm 1.5$ & $19.3 \pm 2.1$ & $28.5 \pm 1.2$ \\
\hline 0.01 & $8.2 \pm 1.4$ & $8.24 \pm 0.9$ & $8.8 . \pm 1.1$ & $21.2 \pm 2.4$ & $29.3 \pm 1.8$ & $18.3 \pm 1.5$ & $14.5 \pm 2.1$ & $22.0 \pm 1.4$ & $40.0 \pm 3.0$ \\
\hline 0.1 & $13.0 \pm 2.3$ & $12.6 \pm 2.8$ & $13.5 \pm 2.3$ & $47.3 \pm 1.2$ & $32.5 \pm 1.1$ & $24.8 \pm 1.9$ & $41.5 \pm 1.9$ & $50.0 \pm 2.1$ & $45.2 \pm 2.1$ \\
\hline 1 & $29.1 \pm 1.1$ & $28.16 \pm 2.1$ & $19.2 \pm 1.3$ & $58.0 \pm 1.9$ & $61.25 \pm 2.1$ & $26.9 \pm 2.4$ & $60.2 \pm 1.1$ & $77.0 \pm 1.8$ & $48.8 \pm 1.8$ \\
\hline 10 & $33.5 \pm 1.9$ & $41.8 \pm 0.7$ & $21.0 \pm 0.9$ & $63.4 \pm 0.9$ & $64.88 \pm 2.7$ & $30.46 \pm 2.9$ & $63.5 \pm 1.8$ & $76.5 \pm 2.4$ & $53.5 \pm 1.1$ \\
\hline 50 & $37.9 \pm 2.8$ & $47.8 \pm 1.2$ & $23.6 \pm 2.1$ & $64.4 \pm 2.4$ & $67.27 \pm 3.4$ & $33.6 \pm 1.8$ & $65.0 \pm 2.1$ & $77.7 \pm 3.1$ & $56.0 \pm 2.4$ \\
\hline 100 & $45.8 \pm 3.0$ & $51.4 \pm 1.8$ & $26.9 \pm 1.7$ & $67.7 \pm 3.4$ & $69.4 \pm 1.7$ & $39.8 \pm 1.3$ & $66.0 \pm 1.7$ & $78.0 \pm 1.7$ & $62.3 \pm 2.5$ \\
\hline 200 & $51.2 \pm 1.4$ & $53.1 \pm 2.1$ & $31.0 \pm 1.3$ & $69.1 \pm 2.4$ & $70.8 \pm 0.9$ & $49.9 \pm 2.9$ & $67.8 \pm 2.3$ & $77.0 \pm 2.4$ & $66.0 \pm 2.7$ \\
\hline 500 & $49.2 \pm 2.7$ & $53.0 \pm 3.2$ & $34.1 \pm 2.9$ & $68.0 \pm 1.5$ & $68.9 \pm 1.4$ & $52.0 \pm 2.0$ & $66.5 \pm 1.9$ & $76.6 \pm 1.5$ & $69.7 \pm 1.8$ \\
\hline 1000 & $45.8 \pm 2.3$ & $50.0 \pm 2.4$ & $36.7 \pm 2.4$ & $66.7 \pm 2.0$ & $68.6 \pm 2.3$ & $54.9 \pm 2.1$ & $66.1 \pm 3.2$ & $76.1 \pm 3.1$ & $72.0 \pm 2.6$ \\
\hline
\end{tabular}

${ }^{a}$ MCF7 (breast cancer), KB (nasopharyngeal carcinoma), K562 (leukemia) with various concentrations for 24-, 48- and 72-h incubation periods Results are expressed as the mean $\pm \mathrm{SD}$.
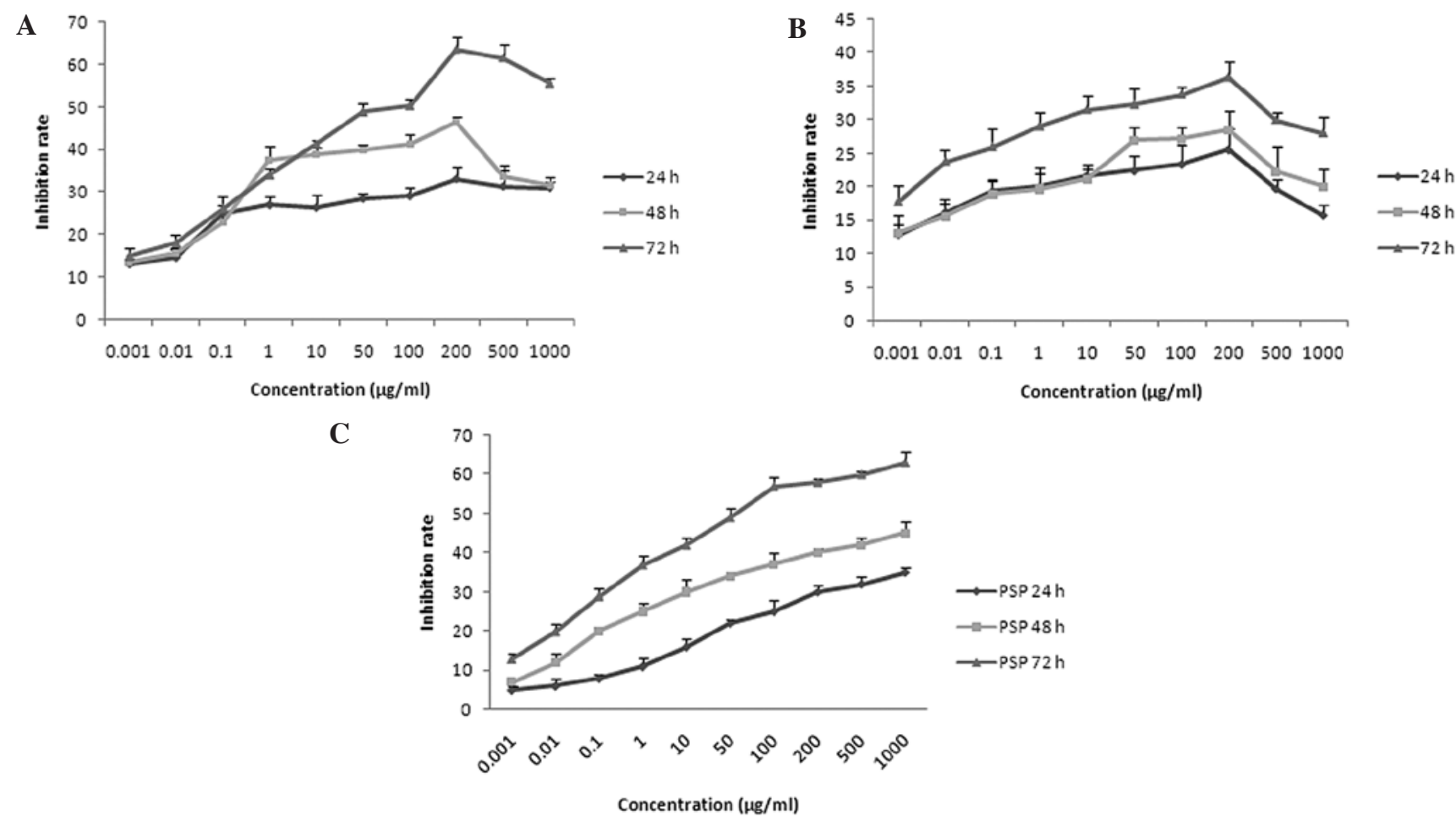

Figure 4. Cytotoxicity profile of PSP001 on in vitro cell lines after 24, 48 and $72 \mathrm{~h}$ incubation as measured by MTT assay. (A) MCF-7 (breast cancer). (B) KB (nasopharyngeal carcinoma). (C) K562 (leukemia). Results were expressed as the mean \pm SD.

most effective method for the study of the activity and action mechanism of the compounds. This assay is relatively easy to use and is suitable for screening of the immune-enhancing potential of novel compounds.

\section{Discussion}

The present study investigated the antioxidant, antitumor and immunomodulatory activities of the polysaccharide isolated from the fruit rind of Punica granatum. Carbohydrates are a relatively untapped source of new drugs and therefore offer promising new therapeutic opportunities. The polysaccharide PSP001 was successfully isolated and characterized from the fruit rind of pomegranate and was found to be easily soluble in water. The factors that determine whether a polysaccharide is likely to exhibit antitumor activity are unclear. However, there appears to be a direct association between the antitumor activity of polysaccharides and their ability to interact with serum albumin (19,30). Since water-soluble polysaccharides were found to be therapeutically applicable (31), PSP001 is ideal for various pharmacological uses due to its immunomodulatory, anticancer and antioxidant properties. 


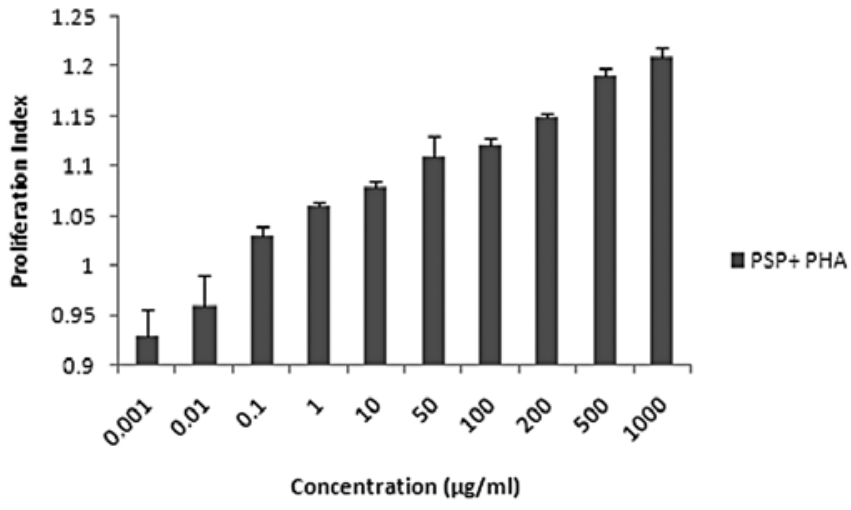

Figure 5. Lymphocyte proliferative activity assay of PSP001 in vitro after $72 \mathrm{~h}$ of incubation. Results are expressed as the mean \pm SD.

Oxidative stress, predominantly caused by an imbalance between the generation of reactive oxygen species (ROS) and antioxidant defence system (32) is the pathology behind the majority of human diseases. Radical scavenging activity is a significant functional property for bioactive compounds (33), and numerous polysaccharides have been reported to have marked antioxidant activity. The antioxidant properties of PSP001 were investigated using various in vitro radical scavenging assays, of which DPPH, FRAP, nitric oxide radical scavenging and linoleic acid emulsion thiocynate assay produced promising results. The DPPH radical scavenging activity is widely used to evaluate the antioxidant capacity of compounds (34). The DPPH radical was considered to be a model of the lipophilic radical and a chain reaction in lipophilic radicals was initiated by lipid autoxidation. PSP001 showed significantly $(\mathrm{p}<0.001)$ high DPPH-scavenging activity compared to the standard ascorbic acid, even at low concentrations and the IC50 values were found to be $44.2 \pm 0.8$ and $149.7 \pm 1.2 \mu \mathrm{g} / \mathrm{ml}$ for PSP001 and ascorbic acid, respectively. PSP001 may be considered to be a potential scavenger against the stable DPPH ions. It appears that PSP001 exhibits hydrogen-donating activities as an antioxidant, as reported for other compounds such as cystine, glutathione, ascorbic acid, and tocopherol (35).

The FRAP assay directly measures antioxidants or reductants in a sample (36). The FRAP assay measures the reducing ability of and antioxidant that reacts with ferric tripyridyltriazine $\left(\mathrm{Fe}^{3+}-\mathrm{TPTZ}\right)$ complex and produces a coloured ferrous tripyridyltriazine ( $\mathrm{Fe}^{2+}$-TPTZ). PSP001 exhibited an increase in antioxidant activity with an increase in concentration as per the FRAP assay. Additionally, inhibition of up to $96.05 \pm 1.1 \%$ at a concentration of $1000 \mu \mathrm{g} / \mathrm{ml}$ was obtained, which was comparable to that of any known antioxidant. Superoxide anions indirectly initiate lipid oxidation as a result of superoxide and hydrogen peroxide, serving as precursors of singlet oxygen and hydroxyl radicals (37) and have also been observed to directly initiate lipid peroxidation (38). Similar to the trend observed with the FRAP assay, PSP001 showed an increase in its radical scavenging ability against superoxide anions with an increase in concentration. PSP001 was not considered to be an effective superoxide anion scavenging compound as its highest activity was only $58 \%$. Lipid peroxidation is the oxidative degradation of polyunsaturated fatty acids and involves the formation of lipid radicals, leading to membrane damage. Free radicals induce lipid peroxidation of polyunsaturated lipids. During the linoleic acid oxidation, peroxides formed and these compounds oxidize $\mathrm{Fe}^{2+}$ to $\mathrm{Fe}^{3+}$. The latter $\mathrm{Fe}^{3+}$ ions form a complex, which results in an intense red colour and has maximum absorption at $500 \mathrm{~nm}$. PSP001 was capable of scavenging the radicals in the linoleic acid emulsion system even up to $72 \mathrm{~h}$ as compared with $24 \mathrm{~h}$ of the standard; its long-lasting action may be promising for use in biological systems where the radicals are generated in a cascade manner. Nitric oxide is a potent pleiotropic mediator of a variety of physiological process and is a diffusible free radical that plays numerous roles as an effector molecule in diverse biological systems, including neuronal messenger, vasodilation and antimicrobial activities (39). Although nitric oxide ions are involved in the host defense, overproduction of this radical contributes to the pathogenesis of certain inflammatory diseases (40). Moreover, these ions form potentially cytotoxic molecules, peroxynitrite. PSP001 was also found to be a good scavenger of nitricoxide ions in a concentration-dependent manner, and an inhibition rate of up to $74.9 \%$ was obtained. Hydroxyl radicals are known to be the most reactive of the reduced forms of dioxygen and are thought to initiate cell damage in vivo (41). These radicals attack proteins, DNA, polyunsaturated fatty acid in membranes and the majority of biological molecules in contact with them (42), are known to be capable of abstracting hydrogen atoms from membrane lipids, and cause peroxidic reaction of lipids. A concentrationdependent increase in activity exhibited by PSP001 against hydroxyl radicals $(63.90 \pm 3.1 \%)$ may be the basis for promising applications in biological systems.

The anticancer properties of PSP001 evaluated on MCF-7 (breast cancer), KB (nasopharyngeal carcinoma) and K562 (leukemia) cells by MTT assay disclosed its therapeutic potential against cancer. The antitumor effects were observed even at low concentrations $(0.001 \mu \mathrm{g} / \mathrm{ml})$ and IC50 values of $97.21 \pm 1.06$ and $52.8 \pm 0.9 \mu \mathrm{g} / \mathrm{ml}$ were obtained on $72 \mathrm{~h}$ incubation for MCF-7 and K562 cells, respectively. PSP001 was not capable of producing an IC50 value in KB cells. PSP001 showed its maximum cytotoxicity at approximately $200 \mu \mathrm{g} / \mathrm{ml}$ for MCF-7 and KB cell lines, whereas in the leukemia cell line K562 it exhibited a dose- and time-dependent increase in activity up to a concentration of $1000 \mu \mathrm{g} / \mathrm{ml}$.

The transformation of a normal to a cancerous cell is likely not a critical event in the genesis of cancer, rather, it is the body's inability to destroy these newly formed cancer cells that lead to tumorigenesis. The majority of newly formed cancer cells do not grow beyond the microscopic stage, as immune cells of the body identify and destroy these cancer cells immediately when they are few in number. The risk of developing cancer is multiplied in cases where the immune system is weak. Thus, any compound that enhances the immune system of the body may be a potential facilitator cancer therapy. The antioxidant and anticancer properties of PSP001 can only be utilized therapeutically if it produces no toxicity to normal cells. The effect of PSP001 on isolated normal lymphocytes at various concentrations revealed that the compound was non-toxic to lymphocytes and also enhanced their proliferation when administered in vitro with a mitogen PHA; a PI of $1.21 \pm 0.01$ at a concentration of $1000 \mu \mathrm{g} / \mathrm{ml}$ was obtained, indicating immunomodulatory activity. Early studies from our 
laboratory revealed that PSP001 is a non-toxic compound to $\mathrm{BALB} / \mathrm{c}$ mice. Conventional anticancer compounds suppress the immune system of the body and a rapid decrease in the lymphocyte count was observed following their administration. For the three biological properties tested with PSP001, the highest activity was found between $200-1000 \mu \mathrm{g} / \mathrm{ml}$. A non-toxic antitumor compound with immunomodulatory and considerable antioxidant activity would be of marked significance in developing an anticancer agent. Therefore, further investigations are required to investigate the antitumor properties of PSP001 and to determine its potential in cancer treatment and management.

\section{Acknowledgements}

We gratefully acknowledge the Council of Scientific and Industrial Research (CSIR) for the research fellowship.

\section{References}

1. Ooi VE and Liu F: Immunomodulation and anti-cancer activity of polysaccharide-protein complexes. Curr Med Chem 7: 715-729, 2000.

2. Lansky E P and Newman RA: Punica granatum (pomegranate) and its potential for prevention and treatment of inflammation and cancer. J Ethnopharmacol 109: 117-206, 2007.

3. Valadares MC, Pereira ERT, Benfica PL and Paula JR Assessment of mutagenic and antimutagenic effects of Punica granatum in mice. Brazil J Pharm Sci 46: 121-127, 2010.

4. Sreelekha TT, Vijayan KK and Balaram P: Antimitotic polysaccharide from Punica granatum. In: Ethnopharmacology - Recent Advances. P Pushpangadan, George V, Janardhanan KK (ed) Daya Publishing House, Delhi, India, pp231-245, 2008.

5. Alho $\mathrm{H}$ and Leinonen J: Total antioxidant activity measured by chemiluminescence method. Methods Enzymol 299: 3-15, 1999.

6. Olukemi OA, Olukemi IO, Sofidiya MO, Aniunoh OA, Lawal BM and Tade IO: Antioxidants activity of Nigerian dietary spices. Electr J Environ Agric Food Chem 496: 1086-1093, 2005

7. Ito N, Fukushima S, Hasegawa A, Shibata $M$ and Ogiso T: Carcinogenicity of butylated hydroxy anisole in F344 rats. J Natl Cancer Inst 70: 343-344, 1983.

8. Ali SS, Kasoju N, Luthra A, Singh A, Sharanabasava H, Sahu A and Bora U: Indian medicinal herbs as source of antioxidants. Food Res Int 41: 1-15, 2008.

9. Couladis M, Tzakou O, Verykokidou E and Harvala C: Screening of some Greek aromatic plants for antioxidant activity. Phytother Res 17: 194-195, 2003.

10. Delanty N and Dichter MA: Antioxidant therapy in neurologic disease. Arch Neurol 57: 1265-1270, 2000.

11. Liu F, Ooi VE and Chang ST: Free radical scavenging activities of mushroom polysaccharide extracts. Life Sci 60: 763-771, 1997.

12. Zhang QB and Zhou GF: In vivo antioxidant activity of polysaccharide fraction from Porphyra haitanesis (Rhodephyta) in ageing mice. Pharmacol Res 48: 151-155, 2003.

13. Peterzegi G, Robert AM and Robert L: Hydroxyl radical as a potential intracellular mediator of polymorphonuclear neutrophil apoptosis. Biomed Pharmacother 57: 130-133, 2003.

14. Franz G: Polysaccharides in pharmacy: current applications and future concepts. Planta Medica 55: 493-497, 1989.

15. Jong SC, Birmingham JM and Pai SH: Immunomodulatory substances of fungal origin. $J$ Immunology and Immunopharmacol 11: 115-122, 1991.

16. Mahady GB: Global harmonization of herbal health claims J Nutr 131: 1120-1123, 2001.

17. Yu ZH, Yin LH, Yang Q and Liu Y: Effect of Lentinus edodes polysaccharide on oxidative stress, immunity activity and oral ulceration of rats stimulated by phenol. Carbohyd Polym 75: $115-118,2009$

18. Wang J, Zuo G, Li J, Guan T, Li C, Jiang R, Xie B, Lin X, Li F, Wang Y and Chen D: Induction of tumoricidal activity in mouse peritoneal macrophages by ginseng polysaccharide. Int J Biol Macromol 46: 389-395, 2010.
19. Chen YG, Shen ZJ and Chen X: Evaluation of free radicals scavenging and immunity-modulatory activities of purslane polysaccharides. Int J Biol Macromol 45: 448-452, 2009.

20. Leung MYK, Liu C, Koon JC.M and Fung KP: Polysaccharide biological response modifiers. Immunol Lett 105: 101-111, 2006.

21. Rao PS, Ghosh TP and Krishna S: Extraction and purification of tamarind seed powder. J Sci Ind Res 4: 705, 1946.

22. Alam N and Gupta PC: Structure of a water-soluble polysaccharide from the seeds of Cassia angustifolia. Planta Medica 50: 308-310, 1986

23. Dubois M, Gilles KA, Hamilton JK, Rebers PA and Smith F: Colorimetric methods for determination of sugars and related substances. Anal Chem 28: 350-356, 1956.

24. Magalhaes LM, Segundo MA, Reis S and Lima JLFC: Automatic method for determination of total antioxidant capacity using 2,2-diphenyl-1-picrylhydrazyl assay. Analytica Chemica Acta 558: 310-318, 2006

25. Benzie IFF and Strain JJ: The ferric reducing ability of plasma (FRAP) as a measure of antioxidant. Anal Biochem 239: 70-76, 1996.

26. Gulcin I, Alici HA and Cesur M: Determination of in vivo antioxidant and radical scavenging activities of propofol. Chem Pharm Bull 53: 281-285, 2005.

27. Green LC, Wagner DA, Glowski J, Skipper PL, Wishnok JS and Tannenbaum SR: Analysis of nitrate, nitrite and $15 \mathrm{~N}$ nitrite in biological fluids. Anal Biochem 126: 131-138, 1982.

28. Kunchandy E and Rao MN: Oxygen radical scavenging activity of curcumin. Int J Pharmacog 58: 237-240, 1990

29. Pan YM, Wang K, Huang SQ, Wang HS, Mu XM, He CH, Ji XW, Zhang $\mathbf{J}$ and Huang FJ: Antioxidant activity of microwaveassisted extract of longan (Dimocarpus longan) peel. Food Chem 106: 1264-1270, 2008

30. Chen YG, Shen ZJ and Chen XP: Modulatory effect of Ganoderma lucidum polysaccharides on serum antioxidant enzymes activities in ovarian cancer rats. Carbohydr Polym 78: 258-262, 2009.

31. Chadha R, Kapoor VK, Thakur D, Kaur R, Arora P and Jain DVS: Drug carrier systems for anticancer agents: a review. J Sci Ind Res 67: 185-197, 2008.

32. Tsuchiya M, Asada A, Maeda K, Ueda Y, Sato EF, Shindo M and Inoue M: Propofol versus midazolam regarding their antioxidant activities. A J Respir Crit Care Med 163: 26-31, 2001.

33. Athukorala Y, Kim KN and Jeon YJ: Antiproliferative and antioxidant properties of an enzymatic hydrolysate from brown alga Ecklonia cava. Food Chem Toxicol 44: 1065-1074, 2006.

34. Prior RL and Cao G: In vivo total antioxidant capacity: comparison of different analytical methods. Free Radic Biol Med 27: 1173-1181, 1999

35. Blois MS: Antioxidant determination by the use of stable free radicals. Nature 181: 1199-2000, 1958.

36. Wong SP and Jen HWK: Antioxidant activities of aqueous extracts of selected plants. Food Chem 99: 775-783, 2006.

37. Okuda T, Kimura Y, Yoshida T, Hatano T, Okuda H and Arichi S: Studies on the activities of tannins compounds from medicinal plants and drugs I. Inhibitory effects on lipid peroxidation in mitochondria and microsomes of liver. Chem Pharm Bull 31: 1625-1631, 1983.

38. Fukuzawa K. Tokumura A, Kogure K, Iemura M, Gondoh N, Fujii M, Ueno S and Shibata A: A comparative study of the ability of ferric nitriloacetate and other iron chelators to assist membrane lipid peroxidation by superoxide radicals. Chem Phys Lipids 110: 69-84, 2001

39. Miller MJ, Dowska Krowicka HS, Chotinaruemol S, Kakkis JL and Clark DA: Amelioration of chronic iletis by nitric oxide synthase inhibition. J Pharmacol Exp Therap 264: 13, 1993.

40. Vliet A and Bast A: Role of reactive oxygen species in intestinal diseases. Free Radic Biol Med 12: 499-513, 1992.

41. Rollet Labelle E, Grange MJ, Elbim C, Marquetty C, Gougerot MA and Pasquier C: Hydroxyl radical as a potential intracellular mediator of polymorphonuclear neutrophil apoptosis. Free Radic Biol Med 24: 563-572, 1998.

42. Wallace SS: Biological consequences of free radical-damaged DNA bases. Free Radic Biol Med 33: 1-14, 2002. 